\title{
Orchestration of Employees' Creativity: A Phased Approach
}

\author{
Charlotte Wehking \\ University of Liechtenstein \\ charlotte.wehking@uni.li
}

\author{
Lena Franziska Kaiser \\ University of Liechtenstein \\ lena.kaiser@uni.li
}

\author{
Bernd Schenk \\ University of Liechtenstein \\ bernd.schenk@uni.li
}

\author{
Jan vom Brocke \\ University of Liechtenstein \\ jan.vom.brocke@uni.li
}

\begin{abstract}
Digital innovation is a promising but challenging way for established organizations to achieve sustainable competitive advantage. A young research stream focuses on the development of innovations by means of employee involvement, which uses the knowledge and creativity of employees. Although it is clear that employees have been innovation drivers, studies on the roles of knowledge and creativity as foundations of employee-driven innovation are all but absent from the literature. Since not all individuals are equally creative, we investigate, through the analytical lens of the model of creativity and innovation, whether domain knowledge matters or if teams lacking domain knowledge can deliver satisfying results, too. The data collection is based on two design-thinking workshops including interviews, observations, and a survey with domain experts who evaluate the prototypes. Opposing to common assumptions of creativity techniques, domain knowledge is fundamental for developing digital innovations.
\end{abstract}

\section{Introduction}

To remain competitive in today's digital business world, companies are challenged to disrupt themselves based on digital innovations [1] as such innovations have a fundamental impact on individuals, organizations, the economy, and the society [2]. Such innovations can be products, processes, or business models that are embodied or enabled by information technology (IT) [3]. Especially, human-centered innovations are desired that match users' needs, are viable for the organization's business strategy, and are technologically feasible [4]. These can be a game changer for disruption, as it can radically change the nature and structure of products and services [1].

Innovations are defined as the successful development and implementation of creative ideas [5].
Creative ideas are rare, so various techniques have been developed with which to extract employees' tacit knowledge and explicate it in a guided process of innovation. One promising approach to foster humancentered digital innovations is the design thinking (DT) method [6, 7], where the promotion of creativity and the participation of different employees play a central role $[8,9]$. DT represents one of the most popular approaches to create human-centered innovations [4] and has received particular attention from multiple organizations as it treats "user-centered problems as entrepreneurial opportunities" [10, p. 2081]. DT is mainly performed in offline settings as factors such as creativity, experimentation, user involvement, and visualization have a great impact on the DT outcome and work best with conventional faceto-face DT [7]. Previous work already recognized the valuable link between digital innovation and DT and started to translate DT in the digital world in digitizing single steps or activities of the DT process (e.g., [11, 12]).

From an organizational view, the participation of employees-those who are not part of the management or innovation team-in the innovation process [13], to increase the organization's innovative power [14], is called employee-driven innovation (EDI). The employees' in-depth knowledge can be used in the development of innovations [15], as they can be creative and spot new opportunities for innovations [16], and their personal networks can be sources of new knowledge and ideas [17]. Unfortunately, EDI often happens in unstructured and spontaneous ways which hinders an appropriate distribution of employees' skills in the innovation process [18].

Further, employees with a strong domain knowledge often work on incremental innovations in an exploitative mode [19], since they are considered as "hidebound and uncreative," [20, p. 98]. Accordingly, radical innovations deliberately build on external sources rather than on internal sources (cf. [21]). Creativity techniques, such as DT, suggest that domain knowledge is not crucial as everybody can participate in a workshop where good results can be achieved and 
successful solutions for a given problem can be developed (e.g., [8, 22]). However, research found out that specific individual skills influence organizational innovation. In particular, these skills are represented by the computational model of creativity and innovation [23, 24], which include domain-relevant skills, creativity-relevant skills, and motivation. This means, the greater the level of these skills, the greater the probability for the innovation to be successful. Against this contradicting background, our research question is as follows: What role do domain-relevant skills, creativity-relevant skills, and motivation play in employee-driven development of digital innovations?

To answer the research question, we chose a mixed-method approach to clarify how the skills of domain experts (hereafter experts only) and nonexperts foster digital innovation. First, we collected qualitative data during two DT workshops through observations, semi-structured interviews, and recordings of the prototype presentations. Second, experts from academia and practice, who did not participate in the workshops, evaluated the prototypes quantitatively based on a survey [25].

We provide important insights into how organizations can use EDI and the employees' knowledge and creativity to achieve competitive advantage for digital innovations. Our findings show that, (1) contrary to existing literature, not all employees should apply DT to develop the same kind of digital innovation, but rather a phased approach should be followed, which also provides guidance and structure for EDI, (2) experts from multiple organizational departments with domain-relevant skills, especially technology-relevant skills, are important for the development of digital innovations, and (3) non-experts are suitable supporters for the development of innovations in an early stage, as they often tend to emerge unintentionally.

\section{Related work}

\subsection{Creativity and knowledge as foundations of innovation}

Confronted with increasingly complex challenges, including accelerating technological development cycles, organizations struggle to structure their innovation processes to improve the quality of their outcomes and reduce their innovations time to market [26]. In particular, the rapid growth of new information technologies has created a focus on digital innovation, as digital technologies can be used in the development process and as a result of the innovation itself [27]. As digital innovations are embedded in an ever-increasing range of products and industries, the role and relevance of IT in any innovation has also increased [1]. The role of managing creativity and knowledge in organizations offers an approach to remedy this challenge [26]. We will provide definitions of each concept and introduce our analytical lens further on.

Knowledge is not only a simple "justified true belief" [28, p. 15], but a "fluid mix of framed experience, values, contextual information, and expert insights that provides a framework for evaluating and incorporating new experiences and information" [29, p. 5]. Knowledge is an important organizational resource because it can have valuable, rare, inimitable, and non-substitutable properties [30]. Creativity helps organizations in updating and developing knowledge by adapting it, arranging it in new ways, or giving it new kinds of sense and value [31].

Creativity is the "production of novel and useful ideas by an individual or small group of individuals working together" [23, p. 126]. The implementation of such creative ideas makes up an organizational innovation [23]. For the promotion of creativity and innovation, Amabile [23] identified three components that are relevant. The corresponding model of creativity and innovation, consists of domain-relevant skills, creativity-relevant skills, and intrinsic-task motivation. Domain-relevant skills, such as factual knowledge, special talent in a domain, and technical skills serve as raw material for creativity. Creativityrelevant skills play an important role in generating creative output from domain-related knowledge. These skills include personal characteristics like selfdiscipline, perseverance, social skills, risk-taking, diverse experience, and personal strategies that help the individual to take new perspectives on a task. Intrinsic-task motivation refers to the individual's baseline attitude about a task and his or her perceptions about undertaking the task. The higher the level of each of the three components, the greater the level of individual creativity and organizational innovation [23]. Besides other, Amabile and Pratt [24] added the components of extrinsic motivation and meaningful work to the model. Extrinsic motivation refers to extrinsic factors that motivate the individual to work on a task (e.g., rewards, recognition), whereas meaningful work refers to work that is significant and positive for the individual [32]. This widely-cited model is firmly anchored in literature and has been applied in many different contexts (e.g., [33]). Accordingly, we use this model as our analytical lens.

As an organization employs many individuals, collective creativity relies heavily on the individuals but is not only the simple aggregation of each team 
member's creativity [34]. Collective creativity includes the social interactions among team members that might trigger new perspectives and interpretations, that any individual may not have thought of alone [35]. In creativity techniques such as DT, this collective creativity appears [9].

\subsection{Employee-driven innovation}

EDI refers to the involvement of a single employee or a joint effort of multiple employees, who do not work in the innovation or R\&D department, in the development and implementation of products, services, and processes [14]. Three streams of EDI are discussed in literature [13]: one that discusses EDI as a bottom-up process in which innovation arises unintentionally in daily work, one that highlights EDI as a mix of bottom-up and top-down processes in which management supports innovation processes initiated by employees, and one that considers EDI as a top-down process in which management motivates employees to be involved in innovation processes. However, striving for innovation can be a challenge for a company, as there are many ways in which innovation processes can be orchestrated to achieve concrete results [36]. One way to orchestrate the innovation process is to use digital technologies (e.g., web-based tools), to encourage the entire workforce to contribute innovative ideas (e.g., [37, 38]).

Besides the particular stream, several drivers of EDI have been identified that foster an innovationfriendly environment in an organization, including organizational culture [39], decision structures, and management support [14], but the individual employee and his or her knowledge remain key to innovation, and little is known to what extent individual competencies influence EDI [40].

From a knowledge and creativity perspective, organizations exploit various sources of new knowledge to stimulate creative ideas for innovation, whereas internal knowledge is central [38]. EDI is a rich source for knowledge exploitation, as there is an interdependence among the acquisition, sharing, and application of knowledge of employees (cf. [41]). If the employees' knowledge is managed properly, EDI is likely to be successful (cf. [38]). Therefore, the analysis of creativity and knowledge (i.e., expertise) is fundamental in the development of digital innovations in the field of EDI.

\section{Research method}

\subsection{Data collection}

To answer our research question, we collected data from two full-day DT workshops (in October 2019), as DT is one of the most commonly used techniques to design human-centered digital innovations [3, 4, 9]. Our workshops provide three data sources: the groups' presented prototypes, individual interviews with the workshop participants, and observations of the group dynamics during the workshops.

The process and methods of DT have been described in various frameworks and models developed by companies such as IDEO and IBM [7]. The most commonly used process model, which was developed by Stanford's d.school [42], distinguishes between five interrelated process steps: empathize, define, ideate, prototype, and test. We relied on this process. Therefore, both workshops had the same goal, strict time management, and structure. First, all groups played a warm-up game (i.e., marshmallow challenge) to create a relaxed and creative atmosphere. Next, we introduced the DT challenge, asking a "how might we" question to support the planned steps of guided mastery in DT [9]. The participants should find application scenarios based on the challenge question: "how might we use virtual reality in DT to enable explorative business process management?" We explicitly stated this question, as it represents specific knowledge domains; virtual reality is used as a technological enabler for the innovation, DT is used as a creativity-technique, and business process management is used as the field of application. The participants were not restricted to develop a solution for a particular industry, department, or a specific process. They went through the DT process from the development of a common challenge understanding to the creation of a prototype.

Each prototype presentation was recorded. In the end, short semi-structured interviews were conducted with the workshop participants to gather additional empirical data. The interviews were based on eight open-ended questions that encouraged participants to elaborate on their expectations, personal experiences, and reflections [43]. In total, 43 interviews were collected with the participants. The average length of an interview was ten minutes. The expert interviews lasted longer in contrast to the non-expert interviews as more detailed information has been considered when answering interview questions. For the observations, each group was accompanied by an observer who filled out a pre-defined questionnaire and took notes of the internal group process and 
dynamics, including, for example, the perceived difficulty level of each phase, the role allocation (e.g., leader, timekeeper), and recording the results of each task of every DT process phase.

In total, 43 individuals voluntarily participated in nine workshop groups. The participants partly knew each other in advance, but have not yet worked together in such a setting. All participants provided their level of expertise in the three domain areas [44]. Accordingly, the participants were divided into three expert groups of four participants each and six nonexpert groups of on average with five participants. Experts were equally distributed to groups to ensure that each domain area was represented, while nonexperts chose their groups freely to avoid bias on the researchers' part. The experts are on average 35 years old, 75 percent were male, they either come from academia or practice in the DACH region (e.g., Hilti, SAP, Swisscom), and worked in one of the three domain areas. The non-experts are on average 25 years old, 70 percent were male, and all were students in a master's program in Information Systems (IS). 58 percent of the non-experts were employed at the time and the others acted as potential employees. With regard to the sampling of our participants, we considered the students as non-experts as suitable, because they faced their study topic of interest (i.e., focusing on digital technologies in organizational setting), they will soon enter work life and they need to tackle such challenges on a daily basis.

\subsection{Data analysis}

The analysis is structured along the three data sources (i.e., prototype, interviews, observation) (Table 1). Each of the three concepts of creativity was measured based on sub-dimensions according to the model of creativity and innovation $[23,24]$.

Table 1. Our data sources regarding the concept of creativity [24, 25]

\begin{tabular}{lccc}
\hline & $\begin{array}{c}\text { Domain- } \\
\text { relevant } \\
\text { skills }\end{array}$ & $\begin{array}{c}\text { Creativity- } \\
\text { relevant } \\
\text { skills }\end{array}$ & Motivation \\
\hline Prototype & $\mathrm{x}$ & $\mathrm{x}$ & \\
Interviews & & $\mathrm{x}$ & $\mathrm{x}$ \\
Observation & $\mathrm{x}$ & $\mathrm{x}$ & $\mathrm{x}$ \\
\hline
\end{tabular}

We focus on groups as the level of analysis. We analyzed the data that could not be analyzed on a group level (e.g., motivation, level of expertise) on the individual level. We summed the individual levels to determine the characteristics of the group, noting group creativity is not a simple aggregation of the creativity of the individuals, as the whole is greater than the sum of its parts [34]. Therefore, we also observed group dynamics.

The prototypes were evaluated independently by six experts who were not part of the workshops (hereafter evaluation experts). The evaluation experts were selected based on their academic or practical experience in the areas of business process- and innovation management, so they were appropriate analysts for the challenge [45]. The average work experience of the evaluation experts is 12 years. The evaluation experts watched the recorded videos of the prototype presentation and evaluated the idea using an evaluation scheme by Dean, Hender, and Rodgers [25]. According to this scheme, the evaluation of an idea refers to four dimensions: (1) workability, which relates an idea's feasibility and ability to be implemented without violating stated constraints; (2) relevance, which focuses on the idea's suitable application to the problem area; and (3) specificity, which refers to a clear and detailed description of the idea; and (4) novelty, which refers to an idea's level of creativity. Each of these dimensions includes two measurable sub-dimensions (see Table 2).

The workshop interviews were transcribed and we used a combination of an open-coding approach and the model of creativity and innovation [23, 24]. We analyzed the interviews with the help of the model and clustered the coded interviews into the areas of personal motivation, task motivation, and work environment. To ensure the coding's traceability, we used the qualitative analysis tool ATLAS.ti. The initial coding provided insights, from which we developed categories and more abstract concepts and related these concepts to each other.

The observations include the results of a standardized questionnaire and photos of all results from all groups. The observers accompanied all groups, took structured notes and photos, that were compared during the analysis. We coded this data with the same categories as the interviews.

From the concept perspective, each concept was measured based on particular sub-dimensions. We assessed domain-relevant skills based on subdimensions such factual knowledge, technical skills, or special talents in the domain. For instance, the items of Dean et al.'s [25] questionnaire (e.g., effectiveness, applicability) or the group observations helped us to assess the domain-relevant skills.

The assessment for the creativity-relevant skills was based on sub-dimensions such as cognitive style, personality characteristics, or cognitive-perceptual style. This included for instance if the participants worked independent, reacted flexible to changes, or in a self-disciplined manner. For instance, the observers were asked to pay attention to how often the groups 
needed external help in order to finish their task or if team members leave the room. Additionally, the interview questions (e.g., "What was the most important driver of innovation today"?) and the prototype with Dean et al.'s [25] items (e.g., originality) further allowed us to assess this concept.

Finally, we considered sub-dimensions such as task motivation, work or social environment to assess the concept of motivation. For instance, we asked the participants during the interviews what they motivated (e.g., "What did you like the most?") or the observers were asked to consider if the participants stay in their groups or whether the participants are quickly distracted (e.g., smartphone).

\section{Findings}

For the purposes of our study, we used the dynamics and results of the DT workshops to clarify the process of developing a digital innovation, how technology is seen as an enabler of an innovation, and whether the quality of solutions developed by experts and non-experts differs. To approach the complex phenomena of creativity and knowledge in the digital innovation process in EDI, we combined the model of creativity and innovation [23, 24] with EDI. Triangulating our data led to three key findings. Our findings are structured based on the concept of creativity and innovation (Table 1).

Finding 1: In the process of developing digital innovations, experts score higher than non-experts in the creation of creative and novel ideas.

Prototypes. The prototype evaluation provides insights into the domain-relevant skills. The evaluation experts independently rated the prototypes based on three dimensions of the framework on idea evaluation [25]—workability, relevance, and specificity - as these dimensions are real-world requirements. The novelty dimension is not included, as it is the key measure of the ideas' creativity and is analyzed separately for the creativity-relevant skills.

The expert groups scored higher in all dimensions than the non-expert groups, except in one subdimension (implementability) (Table 2). Two extreme cases strengthen this insight. The group that scored the highest number of points is an expert group (B), and the group that scored the lowest number of points is a non-expert group (I) (Table 3). Two of the six evaluation experts did not even evaluate the nonexpert group's prototype (I), contending that the group did not present a solution but only a use case. The highest-scoring expert group had the highest score in all sub-dimensions except implementability, where their score was second-highest (Table 2). This second position can be explained by the aim of DT to look for extreme solutions, maximizing benefit and-in doubtnot focusing on implementability. The overall results support our expected direction that experts score higher, but two groups were outliers regarding our expected results. A deeper analysis revealed reasons for these unexpected results. According to the results shown in Table 3, two groups $(\mathrm{C}, \mathrm{F})$ do not fit into the groups' expected outcome, as the non-expert group $(\mathrm{F})$ scored higher than the expert group (C); this expert group also scored much lower than the other two expert groups. After the workshop, the participants of this poorly rated expert group revealed in a discussion that they misinterpreted the survey and determined the level of expertise wrongly, so they may have inaccurately been categorized as experts. The higher score of the non-expert group $(\mathrm{F})$ might have been due to the skills of their interview partner during the define phase, as this highly competent interview partner provided the group with many insights and experiences of his daily work life, having heavy influence on their results.

Observation. The observers recognized that five of the six non-expert (D, E, G, H, I) groups and one expert group (C) had difficulty understanding the problem they were trying to solve. The expert groups understood the challenge and the problem easier because the experts were familiar with all three domain areas and had technical knowledge. This insight also strengthens our first key finding that the experts had deeper and more holistic knowledge about the domains involved in the challenge. Besides the observation that non-experts were lost in the challenge, we noticed that experts could provide knowledge in their own domains but, for example a virtual-reality expert was not able to provide groundbreaking ideas for innovations in the area of business process management. Therefore, the mix of experts in the expert group mattered, although the discussion helped the experts to understand the other domains.

Table 2. Prototype evaluation based on domainrelevant skills [25]

\begin{tabular}{|c|c|c|c|}
\hline Dimension & Sub-dimension & $\begin{array}{c}\text { Mean } \\
\text { of } \\
\text { expert } \\
\text { groups }\end{array}$ & $\begin{array}{c}\text { Mean of } \\
\text { non- } \\
\text { expert } \\
\text { groups }\end{array}$ \\
\hline \multirow{2}{*}{ Workability ${ }^{1}$} & Acceptability & 3.7 & 3.3 \\
\hline & Implementability & 2.7 & 2.8 \\
\hline \multirow{2}{*}{ Relevance $^{1}$} & Applicability & 3.1 & 2.2 \\
\hline & Effectiveness & 2.8 & 2.1 \\
\hline \multirow[b]{2}{*}{ Specificity $^{2}$} & Completeness & 2.3 & 1.8 \\
\hline & $\begin{array}{l}\text { Implicational } \\
\text { explicitness }\end{array}$ & 2.6 & 1.9 \\
\hline \multirow[b]{2}{*}{ Novelty ${ }^{1}$} & Originality & 2.3 & 1.9 \\
\hline & $\begin{array}{l}\text { Paradigm } \\
\text { relatedness }\end{array}$ & 2.3 & 1.8 \\
\hline
\end{tabular}


Table 3. Average points scored per group based on expert evaluation (dimension 1-3)

\begin{tabular}{lllllllll}
\hline \multicolumn{2}{c}{$\begin{array}{c}\text { Dimension } \\
\text { Subdimension }\end{array}$} & \multicolumn{1}{c}{$\boldsymbol{1}$} & \multicolumn{3}{c}{$\mathbf{2}$} & \multicolumn{3}{c}{$\mathbf{3}$} \\
\hline \multirow{6}{*}{ Group } & $\boldsymbol{A}^{*}$ & 4.0 & 3.0 & 3.1 & 2.2 & $\mathbf{3 . 1}$ & $\mathbf{3 . 2}$ & $\boldsymbol{\Sigma}$ \\
\hline & $\boldsymbol{B}^{*}$ & 3.7 & 2.7 & 3.3 & 3.5 & 2.7 & 3.0 & $\mathbf{1 8 . 9}$ \\
& $\boldsymbol{C}^{*}$ & 3.5 & 2.5 & 2.7 & 2.7 & 1.7 & 2.0 & $\mathbf{1 5 . 1}$ \\
& $\boldsymbol{D}^{* *}$ & 3.2 & 2.8 & 2.3 & 2.3 & 2.2 & 2.5 & $\mathbf{1 5 . 3}$ \\
& $\boldsymbol{E}^{* *}$ & 3.5 & 2.9 & 2.3 & 2.0 & 2.0 & 2.0 & $\mathbf{1 4 . 7}$ \\
& $\boldsymbol{F}^{* *}$ & 3.7 & 3.2 & 2.8 & 2.5 & 2.3 & 2.7 & $\mathbf{1 7 . 2}$ \\
& $\boldsymbol{G}^{* *}$ & 3.7 & 3.3 & 2.5 & 2.3 & 1.7 & 1.3 & $\mathbf{1 4 . 8}$ \\
& $\boldsymbol{H}^{* *}$ & 3.5 & 2.8 & 1.7 & 1.8 & 1.5 & 1.3 & $\mathbf{1 2 . 6}$ \\
& $\boldsymbol{I}^{* *}$ & 2.5 & 2.0 & 1.3 & 1.5 & 1.2 & 1.3 & $\mathbf{9 . 8}$ \\
\hline
\end{tabular}

1: Workability, 1.1: Acceptability, 1.2: Implementability;

2: Relevance, 2.1: Applicability, 2.2: Effectiveness;

3: Specificity, 3.1: Completeness, 3.2: Implicational explicitness

* Expert group, ** Non-expert group

Finding 2: In the process of developing digital innovations, experts consider a higher number of perspectives when evaluating a problem than nonexperts do.

Prototypes. The evaluation experts evaluated the originality of the prototypes based on Dean et al. [25] (Table 2). The expert groups received on average of 2.3 points on originality and the non-expert groups received 1.9 points. Table 4 shows the average scored points per group for the novelty dimension. The evaluation experts saw seven out of the nine prototypes as interesting and rated two prototypes (B, F) one category higher, as "unusual, interesting, and showed some imagination" [25, p. 686]. None of the prototypes were evaluated as rare, imaginative, or surprising.

Interviews. The interviews provided several insights into creativity-relevant skills. We analyzed each group separately before performing a cross-case analysis to identify cross-case patterns like similarities and differences between the experts and non-experts. The experts shared that the DT workshop provided a structured setting to think out of the box while keeping the task in mind (e.g., "This has always been the case, we cannot do it this way-and I believe that these barriers or thoughts are put aside, if not eliminated, by methods like DT and open up the space that such an innovation needs"). The opinions of the non-experts differed. Some found DT helpful in solving the challenge step-by-step, others had trouble getting involved in the exercise, expressing that they could not cope with the time pressure or the workshop duration, so they were not concentrating the whole time.

Observation. The observers saw differences between the expert and non-expert groups' creativityrelevant skills. Before the experts started the DT challenge, they exchanged their experiences and thoughts and looked at the challenge from various angles. Most of the non-expert groups had long orientation phases, were often lost, and watched what other groups were doing. They had issues understanding the challenge fully, and instead of figuring it out just considered their first approach as the best. Furthermore, the experts assigned roles for timekeeping and note-taking, while the non-experts sporadically distributed roles - mostly the timekeeper role, although they did not solve their tasks in the required time.

Table 4. Average points scored per group based on expert evaluation (dimension 4)

\begin{tabular}{llll}
\hline $\begin{array}{l}\text { Dimension } \\
\text { Subdimension }\end{array}$ & $\mathbf{4 . 1}$ & $\mathbf{4}$ \\
\hline \multirow{4}{*}{ Group } & $\boldsymbol{A}^{*}$ & 2.0 & $\mathbf{4 . 2}$ \\
& $\boldsymbol{B}^{*}$ & 2.7 & 2.0 \\
& $\boldsymbol{C}^{*}$ & 2.2 & 2.7 \\
& $\boldsymbol{D}^{* *}$ & 2.3 & 2.2 \\
& $\boldsymbol{E}^{* *}$ & 1.8 & 2.3 \\
& $\boldsymbol{F}^{* *}$ & 2.7 & 1.8 \\
$\boldsymbol{G}^{* *}$ & 1.5 & 2.0 \\
& $\boldsymbol{H}^{* *}$ & 1.7 & 1.5 \\
$\boldsymbol{I}^{* *}$ & 1.5 & 1.3 \\
\hline 4: Novelty, 4.1: Originality, 4.2: Paradigm relatedness \\
* Expert group, ** Non-expert group \\
\hline
\end{tabular}

Finding 3: In the process of developing digital innovations, experts are more intrinsically motivated than non-experts are.

Interviews. Self-motivation is key to enhanced creativity [23]. All of the experts who participated in the workshops expressed that they liked the workshops, two stated that they enjoyed the experience, and one participant reported experiencing a certain euphoria (e.g., "I think, a certain euphoria was noticeable from the participants and therefore it was fun and open discussion took place, which motivated me to keep going"). Most of the non-experts found the workshop interesting and fun. The task was well received by the experts because they could relate to the challenge. Work environment is an enabler of intrinsic and extrinsic motivation and may bolster the creative process [24]. For example, some experts told us that their colleagues and managers were excited to hear about their new insights and experiences and wanted to see a short presentation. Therefore, the experts were also extrinsically motivated, as they were expected to present the findings from their "day-off". However, the intrinsic motivation was a stronger driver for the experts than the extrinsic motivation as they told in the interviews. The experts valued inputs from the external interview partners, the other participants' commitment, and the surroundings that helped make innovation possible. The non-experts only criticized the long duration of the workshop. The 
component of meaningful work was addressed by the challenge per se. The topic of the challenge mirrored the participants' areas of interest. The experts work on the topics of virtual reality, DT, or business process management on a daily base in their professions, and the non-experts, students of an IS study program, faced their study topics of interest.

Observation. Regarding the intrinsic task motivation, the observers noticed that all experts participated actively and stayed until the end of the workshop. The experts' personality characteristics also differed from those of the non-experts. While the experts worked as a team in which all members were integrated and had a say, the non-experts were not so strong at teamwork, some members just left their teams, by the end, some groups consisted only of two original members. Moreover, the experts kept to the break specifications, whereas the non-experts came back too late from the break or left during the work periods.

\section{Discussion}

\subsection{Discussion of the findings}

We sought to determine how creativity and knowledge impact the development of digital innovations in the field of EDI. The first part of our discussion is structured along our key findings based on the model of creativity and innovation [23, 24]. First, in the process of developing digital innovations, experts tend to be more creative than non-experts in developing novel ideas. New dynamics, changing environments, and continuous promotion of digital innovation enhance the complexity of problems [1]. To solve such complex problems, organizations must combine effort, creativity, knowledge, and the ability to look at the problem from multiple perspectives [46]. When individuals cannot find a solution on their own, the collective effort helps to produce creative outcomes [35]. We extend Hargadon and Bechky's [35] findings in saying that creative and novel ideas for solving complex problems can be developed only if experts are included in the effort. Especially when innovations are related to technology, it is difficult for an individual who is not familiar with the domain to come up with creative ideas that are also implementable because they are likely to lack deep understanding of the challenge and familiarity with virtual reality-the technology that shapes the solution space-, business process management, or DT. Experts can dive deeply into a problem to understand it and its context fully (i.e., "T-shaped professionals") [47]. Implementability is the only dimension in which nonexperts scored routinely higher than the experts. While this result may not seem plausible at first, as the experts had worked for a longer time and had better ideas about what is possible to implement and what resources are necessary. However, the non-experts presented less complex solutions that did not require a lot of effort and resources to implement. Accordingly, we expect that non-experts, often junior employees, are especially suitable for EDI as a bottom-up process [13] as these innovations include subtle changes in work practices and tend to emerge unintentionally as being more related to daily life struggles and less to domain-specific areas. A phased approach is therefore advisable for organizations, in which non-expert and exports are sequentially part of the innovation process to take advantage of both the unfiltered inspiration of non-experts and the work experience and domainrelevant skills of experts. The insights of a phased approach have implications for the choice of team composition when organizations want to involve employees in the pursuit of digital innovations.

Second, in the process of developing digital innovations, experts consider a higher number of perspectives when evaluating a problem than nonexperts $d o$. The experts not only made a deep dive into the problem based on their domain-relevant skills but also looked at the problem from more angles and made the final solution more comprehensive based on their creativity-relevant skills. The experts combined vertical in-depth knowledge in a specific domain (vertical stroke of " $T$ "), with horizontal capabilities to shift among them (horizontal stroke of "T") [48]. On the other hand, the non-experts made few independent decisions, relying instead several times on the lecturer's approval. They tended to focus on their first idea and did not consider looking at the problem from other perspectives. Our finding contradicts what many creativity techniques promise, as we find that the diversity of a team is not the most driver of a plurality and creativity of ideas (e.g., [8, 22]). Amabile [23] argued that domain-relevant skills are a requisite to developing a suitable idea. However, creativityrelevant skills are also necessary and depend on characteristics like an individual's cognitive style, personality characteristics, cognitive-perceptual style, knowledge of heuristics for generating novel ideas, and work style conducive to creativity.

Third, based on our analysis, the experts were more intrinsically motivated than the non-experts, which we attribute to their being able to relate the challenge to their expertise and see the workshop as an enrichment to their daily life. In contrast, the nonexperts' motivation was low, even though the challenge was related to their master's program so we assumed that they would identify with the task. Motivation is the most straightforward component to 
address in attempts to stimulate creativity [24], which helps to explain why the expert groups' prototypes received higher ratings than the non-experts' ones.

Across all three dimensions, the work environment can influence and stimulate the creativity and outcome of an innovation by providing a level of freedom to carry out work or an encouraging supervisor [49]. Our results were not influenced by this factor, as we gave both workshops according the same structure and performed them in the same room.

\subsection{Implications}

Our study has important implications for practice and research. With reference to implications for research, our study builds on the creativity dimensions $[23,24]$ and applies it in a technology-driven context to develop digital innovations. We contribute to research, especially the stream of EDI, by combining the development of individuals' creative ideas with reference to Amabile's [23] three aspects of innovation and providing a structured approach for EDI, which happens currently mostly spontaneous and unstructured. Besides, we extend the findings of Hargadon and Bechky [35] in proposing that creative and novel ideas for solving complex problems can be developed only if experts are included in the effort.

Our findings disprove the common idea (e.g., [19]) that experts are hidebound and should preferably not be appointed to work in explorative modes (e.g., innovation development). Due to their broad skill set, they are suited from both modes, explorative and exploitative. With this insight, we also respond to a research call from Grisold, Gross, Röglinger, Stelzl, and vom Brocke [50] to investigate which organizational capabilities are crucial for an organization in future, to make organizational processes more opportunity- and stakeholder-driven. We hope that our work serves as a starting point for further research in the field of employee-driven development of digital innovations.

With reference to practical implications, organizations learn that domain and technology knowledge is essential to developing sophisticated ideas for digital innovations. Experts are not only excellent in exploitative improvement in their domain of expertise, but they also are valuable in developing explorative innovations. Experts offer a good mix of "T-shaped" knowledge and so can look at a problem from many perspectives (i.e., creativity-relevant skills). To help non-experts strengthen their creativityrelevant skills, organizations can offer training in applying heuristics or strategies to approach problems or tasks from multiple perspectives. Training on brainstorming could be one such approach [35]. A diverse group that has expertise in the domain areas of interest, masters creative techniques, and can easily motivate themselves is a good start to promoting digital innovation. Motivation of employees might be even more valuable than domain-relevant skills, as employees need motivation to engage their domainrelevant skills and creativity-relevant skills fully in their creative performance.

For educational institutions, our study offers insights based on the work of Amabile [23] and Amabile and Pratt [24]. We emphasize that, especially in an age in which innovation is so often associated with technology, technical, and technological knowledge is indispensable. Experts can understand complex problems that non-experts cannot grasp. Accordingly, we advise a deep-dive-education approach [51] in which educational institutions educate students in particular domain areas to build their domain knowledge. In particular, knowledge in the domain of digital technologies is advisable, as most innovations today are digital and the process of developing an innovation is digital, too [1].

A phased approach is recommended for organizations when striving for digital innovation in which non-experts are first involved in the innovation process to come up with creative ideas without being trapped in domain knowledge. In the second step, experts from multiple departments are involved in the innovation process to further develop the ideas and to take into account for example, technical details or technological dependencies of the innovation. We see potential that non-experts are valuable for bottom-up EDI processes, and experts for top-down EDI processes. But through the phased approach, organizations can achieve optimal results for digital innovation, as the individual parts-experts and nonexperts working separately-are better than the sum of the parts-experts and non-experts working together.

\subsection{Limitations and outlook}

Our study has several limitations, the first of which refers to the number of groups used as a data source. The 43 participants were allocated to nine groups, a small number of groups that makes comparability between groups difficult. We deem the number of participants and groups as sufficient because it is common in literature to use such a number of groups and workshops per se allow the researchers to focus on the groups in detail (cf. [52]).

The second limitation refers to the understanding of the domain of "explorative business process management", which may not yet be deeply anchored in participants' understanding. We counteracted against this problem of understanding, as we briefed 
all participants on all three domains, including explorative business process management and ensured that everybody has a basic understanding of the concept.

The third limitation refers to the use of DT in the data collection process because it is a highly contextualized creativity-technique [6]. However, this technique is widely accepted in practice to provide human-centered digital innovations [7].

Lastly, the groups were diverse in terms of quantity which might impact the study's results. The non-expert groups included more participants per group which might decreased their group performance as for example coordination of all team members was more difficult [53].

Our findings provide first insights into the knowledge and creativity aspects of a digital innovation process. Future research could extend these findings in the form of a case study in order to gain primary data and insights from the organizational environment. Researchers should identify individual skills that are necessary to keep up with or even create digital innovation within organizational realm. Further, not only domain expertise could be focused on but diversity in general, as a broader analytical lens.

\section{References}

[1] S. Nambisan, K. Lyytinen, A. Majchrzak, and M. Song, "Digital Innovation Management: Reinventing Innovation Management Research in a Digital World", MIS Quarterly, 41(1), 2017, pp. 223-238.

[2] R.F. Ciriello, A. Richter, and G. Schwabe, "Digital Innovation", Business \& Information Systems Engineering, 60(6), 2018, pp. 563-569.

[3] R.G. Fichman, B.L. Dos Santos, and Z.E. Zheng, "Digital Innovation as a Fundamental and Powerful Concept in the Information Systems Curriculum", MIS Quarterly, 38(2), 2014, pp. 329-353.

[4] T. Brown, "Design Thinking", Harvard Business Review, 86(6), 2008, pp. 84-92.

[5] M. Baer, "Putting Creativity to Work: The Implementation of Creative Ideas in Organizations", Academy of Management Journal, 55(5), 2012, pp. 1102-1119.

[6] L. Carlgren, M. Elmquist, and I. Rauth, "The Challenges of Using Design Thinking in IndustryExperiences from Five Large Firms", Creativity and Innovation Management, 25(3), 2016, pp. 344-362.

[7] P. Micheli, S.J.S. Wilner, S.H. Bhatti, M. Mura, and M.B. Beverland, "Doing Design Thinking: Conceptual Review, Synthesis, and Research Agenda", Journal of Product Innovation Management, 36(2), 2018, pp. 124148.

[8] T. Brown, Change by Design: How Design Thinking Creates New Alternatives for Business and Society, Harper Collins Business, New York, NY, USA, 2009.
[9] T. Kelley and D. Kelley, Creative Confidence: Unleashing the Creative Potential Within Us All, Harper Collins Business, Croydon, UK, 2014.

[10] H.F.O. von Kortzfleisch, D. Zerwas, and I. Mokanis, "Potentials of Entrepreneurial Design Thinking for Entrepreneurship Education," Proceedings of the 4th International Conference on New Horizons in Education, Rome, Italy, 2013, pp. 2080-2092.

[11] T. Schoormann, J. Hofer, and R. Knackstedt, "Software Tools for Supporting Reflection in Design Thinking Projects", Proceedings of the 53rd Hawaii International Conference on System Sciences, Hawaii, HI, USA, 2020, pp. 407-416.

[12] J.P.A. von Thienen, A. Perlich, J. Eschrig, and C. Meinel, "Smart Documentation with Tele-Board Med", in H. Plattner, C. Meinel, and L. Leifer (eds), Design Thinking Research: Making Design Thinking Foundational, Springer-Verlag, Cham, Switzerland, 2016, pp. 203-233.

[13] S. Høyrup, "Employee-Driven Innovation: A New Phenomenon, Concept and Mode of Innovation" in S. Høyrup, M. Bonnafous-Boucher, C. Hasse, M. Lotz, and K. Møller (eds), Employee-Driven Innovation: A New Approach, Palgrave Macmillan, London, UK, 2012, p. 3-33.

[14] P. Kesting and J.P. Ulhøi, "Employee-Driven Innovation: Extending the License to Foster Innovation", Management Decision, 48(1), 2010, pp. 65-84.

[15] E. Mollick, "The Dynamics of Crowdfunding: An Exploratory Study", Journal of Business Venturing, 29(1), 2014, pp. 1-16.

[16] M. Muller, W. Geyer, T. Soule, S. Daniels, and L.-T. Cheng, "Crowdfunding Inside the Enterprise: Employee-Initiatives for Innovation and Collaboration", Proceedings of the SIGCHI Conference on Human Factors in Computing Systems, Paris, France, 2013, pp. 503-512.

[17] N. Feldmann, H. Gimpel, M. Muller, and W. Geyer, "Idea Assessment via Enterprise Crowdfunding: An Empirical Analysis of Decision-Making Styles", Proceedings of the 22nd European Conference on Information Systems, Tel Aviv, Israel, 2014 pp. 1-10.

[18] V.A. Reibenspiess, K. Drechsler, and K.A. Eckhardt, "A Work Model for Employee-driven Innovation in Public Organizations", Proceedings of the 27th European Conference on Information Systems, Stockholm, Sweden, 2019, p. 1-15.

[19] C. Lettl, "User Involvement Competence for Radical Innovation", Journal of Engineering and Technology Management, 24(1/2), 2007, pp. 53-75.

[20] M. Boden, "Creativity and Knowledge" in A. Craft, B. Jeffrey, and M. Leibling (eds), Creativity in Education, Continuum, London, UK, 2001, p. 95-102.

[21] O. Gassmann, "Opening Up the Innovation Process: Towards an Agenda", R\&D Management, 36(3), 2006, pp. 223-228.

[22] E. von Hippel, "Democratizing Innovation: The Evolving Phenomenon of User Innovation", International Journal of Innovation Science, 1(1), 2009, pp. 29-40. 
[23] T.M. Amabile, "A Model of Creativity and Innovation in Organizations", Research in Organizational Behavior, 10(1), 1988, pp. 123-167.

[24] T.M. Amabile and M.G. Pratt, "The Dynamic Componential Model of Creativity and Innovation in Organizations: Making Progress, Making Meaning", Research in Organizational Behavior, 36, 2016, pp. 157-183.

[25] D.L. Dean, J.M. Hender, and T.L. Rodgers, "Identifying Quality, Novel, and Creative Ideas: Constructs and Scales for Idea Evaluation", Journal of the Association for Information Systems, 7(10), 2006, pp. 646-698.

[26] P. Cohendet, G. Parmentier, and L. Simon, "Managing Knowledge, Creativity and Innovation", in H. Bathelt, P. Cohendet, S. Henn, and S. Kaurent (eds), The Elgar Companion to Innovation and Knowledge Creation, Edward Elgar Publishing, Northampton, MA, USA, 2017, p. 197-214.

[27] A. Hevner and S. Gregor, "Envisioning Entrepreneurship and Digital Innovation Through a Design Science Research Lens: A Matrix Approach", Information \& Management, 2020, pp. 103350.

[28] I. Nonaka, "A Dynamic Theory of Organizational Knowledge Creation", Organization Science, 5(1), 1994, pp. 14-37.

[29] T.H. Davenport and L. Prusak, "Working Knowledge: How Organizations Manage What They Know", Harvard Business Press, Boston, MA, USA, 1998.

[30] J. Barney, "Firm Resources and Sustained Competitive Advantage", Journal of Management, 17(1), 1991, pp. 99-120.

[31] P. Saulais and J.-L. Ermine, "Creativity and Knowledge Management", Vine, 42(3/4), 2012, pp. 416-438.

[32] B.D. Rosso, K.H. Dekas, and A. Wrzesniewski, "On the Meaning of Work: A Theoretical Integration and Review", Research in Organizational Behavior, 30, 2010, pp. 91-127.

[33] S.J. Ashford, B.B. Caza, and E.M. Reid, "From Surviving to Thriving in the Gig Economy: A Research Agenda for Individuals in the New World of Work", Research in Organizational Behavior, 38, 2018, pp. 2341.

[34] R.W. Woodman, J.E. Sawyer, and R.W. Griffin, "Toward a Theory of Organizational Creativity", Academy of Management Review, 18(2), 1993, pp. 293-321.

[35] A.B. Hargadon and B.A. Bechky, "When Collections of Creatives Become Creative Collectives: A Field Study of Problem Solving at Work", Organization Science, 17(4), 2006, pp. 484-500.

[36] I. Bäckström and M. Lindberg, "Varying Involvement in Digitally Enhanced Employee-driven Innovation", European Journal of Innovation Management, 22(3), 2019, pp. 524-540.

[37] Y. Yoo, R.J.Jr. Boland, K. Lyytinen, and A. Majchrzak, "Organizing for Innovation in the Digitalized World", Organization Science, 23(5), 2012, pp. 1398-1408.

[38] J.L. Gressgård, O. Amundsen, T.M. Aasen, and K. Hansen, "Use of Information and Communication Technology to Support Employee-Driven Innovation in
Organizations: A Knowledge Management Perspective", Journal of Knowledge Management, 18(4), 2014, pp. 633-650.

[39] S.A. Zahra, "Predictors and Financial Outcomes of Corporate Entrepreneurship: An Exploratory Study", Journal of Business Venturing, 6(4), 1991, pp. 259-285.

[40] S. Mitchelmore and J. Rowley, "Entrepreneurial Competencies: A Literature Review and Development Agenda", International Journal of Entrepreneurial Behaviour \& Research, 16(2), 2010, pp. 92-111.

[41] T.M. Aasen, O. Amundsen, L.J. Gressgård, and K. Hansen, "In Search of Best Practices for EmployeeDriven Innovation: Experiences from Norwegian Work Life", in S. Høyrup, M. Bonnafous-Boucher, C. Hasse, M. Lotz, and K. Møller (eds), Employee-Driven Innovation, Palgrave Macmillan, London, UK, 2012, pp. 57-74.

[42] Stanford d.school, "Design Thinking Bootleg", retrieved from https://dschool.stanford.edu/ resources/design-thinking-bootleg, 2018.

[43] G. Paré, "Investigating Information Systems with Positivist Case Research", Communications of the Association for Information Systems, 13(1), 2004, pp. 233-264.

[44] S.E. Dreyfus and H.L. Dreyfus, "A Five-Stage Model of the Mental Activities Involved in Directed Skill Acquisition. Berkeley", University of California Press, CA, USA, 1980.

[45] T.M. Amabile, "The Social Psychology of Creativity: A Componential Conceptualization Technique", Journal of Personality and Social Psychology, 45(2), 1983, pp. 327-376.

[46] S.L. Brown and K.M. Eisenhardt, "Competing on the Edge: Strategy as Structured Chaos", Long Range Planning, 31(5), 1998, pp. 786-789.

[47] S. Barile, G. Franco, G. Nota, and M. Saviano, "Structure and Dynamics of a "T-Shaped" Knowledge: From Individuals to Cooperating Communities of Practice", Service Science, 4(2), 2012, pp. 161-180.

[48] D. Guest, "The Hunt is on for the Renaissance Man of Computing", The Independent, 17(9), 1991.

[49] T.M. Amabile, R. Conti, H. Coon, J. Lazenby, and M. Herron, "Assessing the Work Environment for Creativity", Academy of Management Journal, 39(5), 1996, pp. 1154-1184.

[50] T. Grisold, S. Gross, M. Röglinger, K. Stelzl, and J. vom Brocke, "Exploring Explorative BPM-Setting the Ground for Future Research", Proceedings of the 17th International Conference on Business Process Management, Vienna, Austria, 2019, pp. 23-31.

[51] E. Heinemann, "Educating T-shaped Professionals", Proceedings of the 15th American Conference on Information Systems, San Francisco, CA, USA, 2009, pp. $1-8$.

[52] R. Ørngreen and K. Levinson, "Workshops as a Research Methodology", Electronic Journal of Elearning, 15(1), 2017, pp. 70-81.

[53] A.G. Ingham, G. Levinger, J. Graves, and V. Peckham, "The Ringelmann Effect: Studies of Group Size and Group Performance", Journal of Experimental Social Psychology, 10(4), 1974, pp. 371-384. 